DOI: $10.17957 / \mathrm{IJAB} / 15.1765$

http://www.fspublishers.org

\title{
Isolation, Propagation and Biocontrol Activity of Indigenous Bacteriophages against Brucella abortus
}

\author{
Arfat Yousaf Shaheen ${ }^{1}$, Ali Ahmad Sheikh ${ }^{1 *}$, Masood Rabbani ${ }^{1}$, Wasim Shehzad ${ }^{2}$, Zaigham Abbas ${ }^{3}$ and Munazzah \\ Maqbool $^{1}$ \\ ${ }^{1}$ Institute of Microbiology, University of Veterinary and Animal Sciences, Sheikh Abdul Qadir Jelani Road Lahore Pakistan \\ ${ }^{2}$ Institute of Biochemistry and Biotechnology, University of Veterinary and Animal Sciences, Sheikh Abdul Qadir Jelani Road \\ Lahore Pakistan \\ ${ }^{3}$ Department of Microbiology \& Molecular Genetics, Canal Bank Rd, Punjab University New Campus, Lahore Punjab \\ *For correspondence: ali.ahmad@uvas.edu.pk \\ Received 17 November 2020; Accepted 18 January 2021; Published 16 April 2021
}

\begin{abstract}
Brucellosis, being a zoonotic disease, is difficult to control despite the availability of vaccines. Bovine brucellosis could be controlled effectively using brucellaphages. This study was conducted to isolate bacteriophages against Brucella abortus from cattle farms sewage/slurry samples $(\mathrm{n}=50)$. Isolation and propagation of brucellaphages was made through spot and plaque assay. Two samples $(n=2)$ were found positive on the plates as circular, clear, and pinpoint plaques $(0.3$ to 0.5 mm $)$ with $4.6 \times 10^{6} \mathrm{PFU} / \mathrm{mL}$ of brucellaphage titre against Brucella abortus RB51. One- step growth experiments revealed latent period of $120 \mathrm{~min}$ and burst size of 93 and 114 PFU for two isolated brucellaphages ( $\phi \mathrm{P} 1$ and $\phi \mathrm{P} 2)$ respectively. These phages were unable to lyse Staphylococcus aureus, Streptococcus spp., Salmonella spp., Escherichia coli, Bacillus subtilis and Pasteurella multocida. Isolated brucellaphages were stable up to $60^{\circ} \mathrm{C}$ and between 7 to $9 \mathrm{pH}$. No loss in phage titres were observed at $4^{\circ} \mathrm{C}$ but phage titres were reduced by one $\log$ at $\left(-20^{\circ} \mathrm{C}\right)$ overnight. There was no effect of SM buffer, normal saline and EDTA on stability of brucellaphages and addition of divalent salts in medium showed significant increase in PFU. However, treatment with SDS and chloroform destroyed the phages in one hour exposure. The phages were found carrying double stranded DNA ( 40 kb size) and two prominent protein bands of $45 \mathrm{kDa}$ and $70 \mathrm{kDa}$. Biocontrol activity of brucellaphages showed average Brucella abortus count reduction to $4.5 \times 10^{3}$ from $5.0 \times 10^{8} \mathrm{CFU} / \mathrm{g}$ of soil sample within $48 \mathrm{~h}$ when treated with maximum phage titre of $5.0 \times 10^{11} \mathrm{PFU} / \mathrm{mL}$. Hence, this study revealed that brucellaphages are present in our environment and can potentially be consider for their cost-effective practical applications in inactivation of Brucella abortus after comprehensive experimental evaluations. (c) 2021 Friends Science Publishers
\end{abstract}

Keywords: Brucellosis; Brucellaphages; Brucella abortus; Overlay technique; Characterization; Biocontrol activity

\section{Introduction}

Bovine brucellosis is a significant bacterial disease with zoonotic potential and economic importance worldwide and is mainly caused by Brucella abortus. B. abortus is a small, non-motile, non-sporing, gram negative, facultative intracellular coccobacilli of the genus Brucella. Brucella is a member of the Brucellaceae family, in the order Rhizobiales and class Alphaproteo bacteria. Main routes of transmission of Brucella organism is through mucous membranes, ingestion and also from broken skin. Among various infectious diseases, brucellosis is one of the topranked bacterial diseases prevalent in developing countries. It is a highly contagious, chronic infectious disease in animals and among zoonotic diseases, it ranked at second position (OIE 2019). The most common consequences of bovine brucellosis are last trimester abortions, retained placenta, metritis, infertility, orchitis and epididymitis in animals, hence producing economic losses to livestock sector in terms of abortion, low fertility rate, decrease milk yield and loss due to replacement of the animal (Dean et al. 2012; Manish et al. 2013).

Being zoonotic, it can be transferred to humans through direct contact with infected animal material or indirectly by ingestion of contaminated dairy products. In countries like Pakistan, importance of the disease is more as majority of rural population is involved in livestock farming (Shafee et al. 2011). Seroprevalence of 18.6 and $8.7 \%$ was studied in herds and animals respectively in various districts of Pakistan (Ali et al. 2017; Arif et al. 2019). Efforts are made to control the problem in endemic areas by using two commercially available live vaccines (RB51 and S19), but these vaccines are not producing desirable results and being live vaccines, these cause abortions in pregnant animals and

To cite this paper: Shaheen AY, AA Sheikh, M Rabbani, W Shehzad, Z Abbas, M Maqbool (2021). Isolation, propagation and biocontrol activity of indigenous bacteriophages against Brucella abortus. Intl J Agric Biol 25:1066-1074 
also have unwanted effects in humans exposed to the vaccines. The effective control of brucellosis is by eradication program. However, this procedure cannot be employed in developing countries like Pakistan due to high cost of animals (Cutler 2005).

Bacteriophages have been found to be potential candidates for prevention and treatment of many bacterial diseases. The phages are very specific to their host and only target specific bacteria and this specificity make them unique by not targeting human and other animal cells (Chachra et al. 2012; Filippov et al. 2013). Previous literature had studies regarding the bacteriophage-based diagnostics, phage typing, and epidemiological investigation of brucellaphages (Gupta and Saxena 2017a; Sergueev et al. 2017). Most of the studies were about the genetic diversity among previously characterized reference brucellaphages ( Tb, Bk, R/C, Wb, Fi, Iz, Pr) but remains limited about the successful use of brucellaphages for specific decontamination and antibacterial therapy (Hammerl et al. 2017). Few studies have been concerned with the use of specific bacteriophage for prophylaxis and therapy against brucellosis (Chachra et al. 2012; Pandey et al. 2013; Prajapati et al. 2014; Jain et al. 2015; Gupta and Saxena 2017b; Saxena and Raj 2018). However, there is not any study conducted so far regarding the use of specific bacteriophage for the biocontrol of brucellosis with an idea of reducing Brucella contamination in livestock and dairy farms. The past studies encouraged us to isolate bacteriophages active against $B$. abortus in our country. So, objectives of our first study in Punjab, Pakistan were to isolate, propagate and evaluate biocontrol activity of bacteriophages against $B$. abortus, which may be fruitfully, applied in future studies of field applications of brucellaphages for the control of bovine brucellosis.

\section{Materials and Methods}

\section{Location}

This study was conducted at the University Diagnostic Laboratory (UDL), University of Veterinary and Animal Sciences (UVAS), Lahore, Pakistan from the year 20172019.

\section{Samples}

Samples of sewage water/slurry $(n=50)$ were collected from Brucella suspected livestock farms, Punjab under strict safety measures recommended in OIE (2018). Out of 50 collected samples, 42 samples were of slurry (semi-liquid mixture of manure) and 8 were of sewage drainages of Lahore.

\section{Host strain identification}

Live vaccine of bovine Brucella abortus (RB51) was purchased from local veterinary drug store and was used as host strain, under strict biosafety precautions as per recommended in OIE (2019). Growth of B. abortus on solid media was obtained by inoculating $0.2 \mathrm{~mL}$ of vaccine (RB51) on Tryptose Soy Agar (TSA) (Merck Millipore, Germany) and incubated aerobically at $37^{\circ} \mathrm{C}$ for 3 to 5 days (Saxena and Raj 2018). To attain the sufficient bacterial turbidity $\left(\mathrm{O} . \mathrm{D}_{600}=0.8\right)$, different conditions were tested included tube cultures and cultures in flasks by giving inoculation in test tube and conical Erlenmeyer flask. Liquid culture of $B$. abortus was obtained by inoculating the loopful culture (single colony) of RB51 strain from TSA plate in Tryptose Soy Broth (TSB) (Merck Millipore, Germany) in conical Erlenmeyer flask, filled as 1/5 of their nominal volume and incubated at $150 \mathrm{rpm}, 37^{\circ} \mathrm{C}$ overnight (Sergueev et al. 2017). RB51 strain was identified based on its characteristic of resistance to rifampicin antibiotic by growing on rifampicin added TSA medium $(250 \mu \mathrm{g} / \mathrm{mL})$ and incubated at $37^{\circ} \mathrm{C}$ for $72 \mathrm{~h}$ (OIE 2019). For further confirmation, PCR was performed for the IS711 repetitive genetic region of bacterial genome. Bacterial DNA isolated using QIAamp DNA Mini kit (QIAGEN) was amplified as per method of (O'Leary et al. 2006). Thermocycler (BIORAD $\mathrm{T} 100^{\mathrm{TM}}$ ) was programmed according to conditions as mentioned in Table 1.

\section{Isolation and propagation of bacteriophages}

Briefly, $50 \mathrm{~mL} 2 \mathrm{X}$ TSB, $40 \mathrm{~mL}$ slurry supernatant and 10 $\mathrm{mL}$ of broth culture of RB51 (log phase=24 h) having $\left(\mathrm{O} \mathrm{D}_{600}=0.8\right)$ were added and incubated at $37^{\circ} \mathrm{C}, 120 \mathrm{rpm}$ for 10 days. $10 \mathrm{~mL}$ sample was drawn out on alternate days i.e., (2, 4, 6 and so on up to 10 days), and checked for presence of bacteriophages through spot assay (Chachra et al. 2012). Propagation of bacteriophages was carried out by giving successive enrichment to filtrates found positive in spotting, for three to four times with RB51 strain (Texas 2011). Subsequently, plaque assay was performed, using double agar overlay technique to observe plaques. Optimum adsorption time of phage with RB51 was determined by incubating the mixture of filtrate and RB51 at $37^{\circ} \mathrm{C}$ at varied adsorption time $(15,30,60,90$ and $120 \mathrm{~min})$ before adding into soft agar containing $0.05 \mathrm{M} \mathrm{CaCl}_{2}$ and $\mathrm{MgCl}_{2}$ to the final concentrations. Semisolid TSB with $0.65 \%$ wach of agarose and bacteriological agar (maintained at $45^{\circ} \mathrm{C}$ in water bath) were used as soft agar for overlaying and both formulations were compared for good recovery of plaques on them (Yang et al. 2010).

\section{Titration and purification of brucellaphages}

Phage titre was measured through plaque assay by serially diluting the sterile phage filtrates to six different dilutions $\left(10^{-1}-10^{-6}\right)$ in TSB as described by (Gupta and Saxena 2017a). Purification of phages was carried out by three-fold successive single plaque separation until homologous plaques were obtained (Hamza et al. 2016). Results for all 
Table 1: Thermo cycler conditions for PCR

\begin{tabular}{llll}
\hline Stages & \multicolumn{2}{c}{ PCR conditions } & Cycles \\
\cline { 2 - 3 } & Temp. & Time & \\
\hline Initial Denaturation & $95^{\circ} \mathrm{C}$ & $5 \mathrm{~min}$ & 1 \\
Denaturation & $95^{\circ} \mathrm{C}$ & $1.15 \mathrm{~min}$ & \\
Annealing & $55.5^{\circ} \mathrm{C}$ & $2 \mathrm{~min}$ & 30 \\
Extension & $72^{\circ} \mathrm{C}$ & $2 \mathrm{~min}$ & \\
Final extension & $72^{\circ} \mathrm{C}$ & $10 \mathrm{~min}$ & 1 \\
\hline
\end{tabular}

the experiments i.e., morphology of the plaques, host range, temperature and $\mathrm{pH}$ stability, molecular characterization and biocontrol activity were compared with the positive control brucellaphage strain, Tbilisi (Tb) phage obtained from Felix d' Herelle Reference Center for Bacterial Viruses (Laval University, QC, Canada) (Sergueev et al. 2017).

\section{One-step phage growth curve and burst size}

One-step growth experiments were conducted according to Wong et al. (2014) with modifications on time points and adsorption. A mid-log phase bacterial culture was infected with a phage suspension to a MOI ratio of 0.1 . The mixture was incubated for $30 \mathrm{~min}$ at $37^{\circ} \mathrm{C}$, with shaking at $120 \mathrm{rpm}$ and was subsequently centrifuged at $7000 \times \mathrm{g}$ for $5 \mathrm{~min}$. The supernatant was used for the determination of unabsorbed phage titre by the agar overlay assay. To determine the one-step growth kinetics of the phages, infected phages were obtained by centrifugation at $7000 \times \mathrm{g}$ for $5 \mathrm{~min}$ at $4^{\circ} \mathrm{C}$. The infected phages were resuspended in an equal volume of pre-warmed TSB medium and then incubated at $37^{\circ} \mathrm{C}$ with agitation. After every $30 \mathrm{~min}$, for up to $4 \mathrm{~h}$, the sample was withdrawn and assessed for phage titre using double agar overlay assay. The phage titres were then plotted against time intervals (Wong et al. 2014).

\section{Heterogeneous bacterial species specificity of brucellaphages}

Host range of isolated brucellaphages ( $n=2$ positive) $(\phi P 1$ and $\phi \mathrm{P} 2$ ) was checked against heterogeneous bacterial species of veterinary importance viz., Pasteurella multocida (ATCC® $43137^{\mathrm{TM}}$ ), Staphylococcus aureus (ATCC® $23235^{\mathrm{TM}}$ ), Streptococcus sp. (ATCC® $9884^{\mathrm{TM}}$ ), E. coli (ATCC® $25922^{\mathrm{TM}}$ ), Salmonella spp. (ATCC® $35664^{\mathrm{TM}}$ ) and Bacillus subtilis (ATCC® $23857^{\mathrm{TM}}$ ) (Chachra et al. 2012).

\section{Stability of brucellaphages}

Thermal stability of phages ( $\phi \mathrm{P} 1$ and $\phi \mathrm{P} 2)$ was checked by incubating phage suspensions in TSB $(\mathrm{pH}=7.0)$ at various temperatures $\left(25,37,45,60,70,80,90^{\circ} \mathrm{C}\right)$ for one hour. Stability of phages at low temperatures i.e., $-20^{\circ} \mathrm{C}$ and $4^{\circ} \mathrm{C}$ was observed overnight. $\mathrm{pH}$ stability of phages $(\phi \mathrm{P} 1$ and $\phi \mathrm{P} 2)$ was determined by incubating phage suspensions in TSB, adjusted in steps of $1 \mathrm{pH}$ unit from $\mathrm{pH} 2$ to 9 , for one hour at $37^{\circ} \mathrm{C}$. Effect of treatment with organic solvents was studied by incubating phage suspension with an equal volume of Sodium Dodecyl Sulphate (SDS) (10\%), chloroform and EDTA $(0.01 \mathrm{M})$ for one hour at $37^{\circ} \mathrm{C}$. Effect of osmotic shock and inorganic salts was evaluated by incubating the phage suspensions in Saline Magnesium (SM) buffer (100 m $M$ NaCl, $25 \mathrm{~m} M$ Tris- $\mathrm{HCl}$ pH 7.5, $8 \mathrm{~m} M$ $\mathrm{MgSO}_{4}$ ) and 0.5 molar concentrations of Sodium chloride $(\mathrm{NaCl})$, Calcium chloride $\left(\mathrm{CaCl}_{2}\right)$, and Magnesium chloride $\left(\mathrm{MgCl}_{2}\right)$ respectively overnight at $37^{\circ} \mathrm{C}$. Phage-free and bacterial-free suspensions were used as controls incubated under the same conditions as the phage-bacterial suspensions (Chachra et al. 2012; Hamza et al. 2016). Subsequently, phage titres were checked by double agar overlay method.

\section{Brucellaphages genome and proteins characterization}

Phage genome was extracted by PCI (phenol-chloroformisoamyl alcohol) method. Extracted genome was subjected to digestion with DNase I, RNase A and S1 nuclease (Thermo Scientific, U.S.A.) (Zhu et al. 2009). Restriction endonuclease analysis was carried out by incubating about 1 $\mu \mathrm{g}$ of each DNA sample with approximately $1 \mu \mathrm{L}$ of FastDigest $^{\mathrm{TM}}$ restriction enzymes HindIII and EcoRI (Thermo Fisher Scientific, U.S.A.) for $2 \mathrm{~h}$ at $37^{\circ} \mathrm{C}$ (Wang et al. 2018). The purified phage preparation $\left(1 \times 10^{10} \mathrm{PFU} / \mathrm{mL}\right)$ and the host strain were analyzed for proteins characterization through sodium dodecyl sulphate polyacrylamide gel electrophoresis (SDS-PAGE) (Zhu et al. 2009).

\section{Evaluation of biocontrol activity of brucellaphages}

Biocontrol activities of brucellaphages were determined against live cultures of $B$. abortus RB51 and B. abortus S99 strains mixed in farm soil in sham (lab-based field conditions). For sham experiment, soil sample (100 g) from dairy farm was collected and sterilized through autoclave before inoculating it with $20 \mathrm{~mL}$ volume of broth culture of bacteria in $\log$ phase containing $5 \times 10^{8} \mathrm{CFU} / \mathrm{mL}$ of $B$. abortus strains and treated with $\phi \mathrm{P} 1$ and $\phi \mathrm{P} 2$ phages. Immediately after bacterial inoculation, phage suspensions with specified titres i.e., $5 \times 10^{11}, 5 \times 10^{8}$, and $5 \times 10^{5} \mathrm{PFU} / \mathrm{mL}$ for each of phage were tested for bacterial count reductions by adding in bacteria inoculated soil sample. Pre and post treatment counts of $B$. abortus in farm soil were estimated through viable plate count. Bacterial count reduction was observed at $12,24,36,48$ and $72 \mathrm{~h}$ time points at $37^{\circ} \mathrm{C}$. $\mathrm{Tb}$ phage was tested as control phage with same conditions applied for $\phi \mathrm{P} 1$ and $\phi \mathrm{P} 2$. Phage-free and bacterial-free suspensions were used as controls incubated under the same conditions as the bacteria-phage treated soil samples.

\section{Statistical analysis}

Results for two assays (Spot and Plaque) were compared 
through McNemar Test, and one-way analysis of variance (ANOVA), with 95\% confidence interval was used for comparing temperature and $\mathrm{pH}$ stability of phages as well as for biocontrol activity by using statistical package for social sciences (S.P.S.S.) version 23.0.

\section{Results}

Pure culture of B. abortus with isolated colonies (round, small, translucent and a pale honey colour colonies of 0.5 $\mathrm{mm}$ diameter) was observed on TSA appeared after $72 \mathrm{~h}$ of incubation. It was observed that turbidity in test tube was 0.2 at $\mathrm{O}^{-\mathrm{D}_{600}}$ in TSB at $37^{\circ} \mathrm{C}$ up to $48 \mathrm{~h}$ but it was enhanced to $\mathrm{O}^{\mathrm{D}} \mathrm{D}_{600}=0.8$ with $\mathrm{TSB}$ in $24 \mathrm{~h}$ at $37^{\circ} \mathrm{C}$ and shaking at 150 rpm in conical Erlenmeyer flask. Growth of RB51 strain was found on TSA plates containing rifampicin antibiotic. Upon further confirmation on molecular basis through PCR, product (amplicon) size of $498 \mathrm{bp}$ for IS711 gene for $B$. abortus was observed (Fig. 1).

Seven samples were found positive in screening (spot method) as clear zones of lysis apparent on the plates indicated the presence of viable bacteriophages against $B$. abortus (Fig. 2) and two of the seven screened samples gave positive plaques in plaque assay on the $6^{\text {th }}$ day of incubation. Out of these 7 positive samples, 1 sample was found positive from sewage samples $(n=8)$ tested and remaining 6 positive samples were of slurry samples $(n=42)$ of livestock farms. In our first attempt of plaque assay, pinpoint and hazy plaques of bacteriophages were observed with soft agar (TSB containing $0.65 \%$ bacteriological agar) (Fig. 3a). However, in second attempt of using soft agar preparation with $0.65 \%$ agarose, we obtained the clear pinpoint plaques of diameter $0.5 \mathrm{~mm}$ as compared to soft agar preparation with $0.65 \%$ bacteriological agar (Fig. 3b).

Plaque morphology of isolated brucellaphages $(n=2)$ was similar to that for $\mathrm{Tb}$ phage. $\mathrm{Tb}$ phage produced pinpoint, round and clear plaques of $0.5 \mathrm{~mm}$ diameter but reached maximum of $2.0 \mathrm{~mm}$ after $48 \mathrm{~h}$ of incubation with B. abortus. Optimum adsorption time for the brucellaphages was determined to be $120 \mathrm{~min}$ in this study as maximum plaques $\left(4.5 \times 10^{-6} \mathrm{PFU} / \mathrm{mL}\right)$ were recovered in $120 \mathrm{~min}$. Results for two assays (Spot and Plaque) were compared, and statistically non-significant $0.062(P>0.05)$ value was obtained indicating that there is no significant difference between plaque assay and spot assay. The latent time of $\phi \mathrm{P} 1, \phi \mathrm{P} 2$, and $\mathrm{Tb}$ was estimated to be 120,120 and $90 \mathrm{~min}$ respectively, while the burst size of these phages was 93, 114 and 122 PFU per infected cell, respectively (Fig. 4).

Host range of brucellaphages revealed that they are unable to lyse heterologous bacterial species. Testing of the thermal stability of $\phi \mathrm{P} 1$ and $\phi \mathrm{P} 2$ phages revealed their viability up to $60^{\circ} \mathrm{C}$ but when exposed to $70^{\circ} \mathrm{C}$, their viability starts decreasing (Fig. 5). In comparison, Tb phage had stability up to the $80^{\circ} \mathrm{C}$ but beyond $80^{\circ} \mathrm{C}$ it was inactivated in one hour exposure. It was observed that refrigeration temperature $\left(4^{\circ} \mathrm{C}\right)$ did not affect the plaque

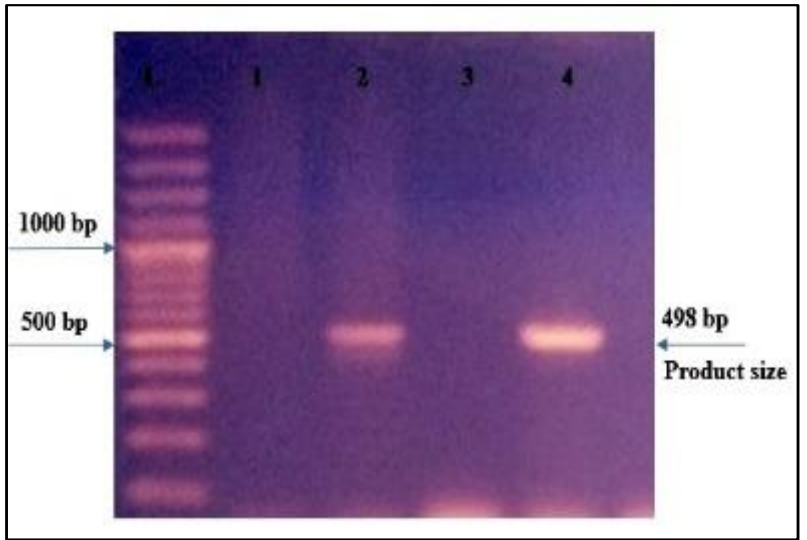

Fig. 1: Molecular identification of B. abortus through PCR, L: 100 bp DNA Ladder, 1: negative control, 2: RB51 vaccine DNA, 3: negative sample 4: RB51 culture DNA

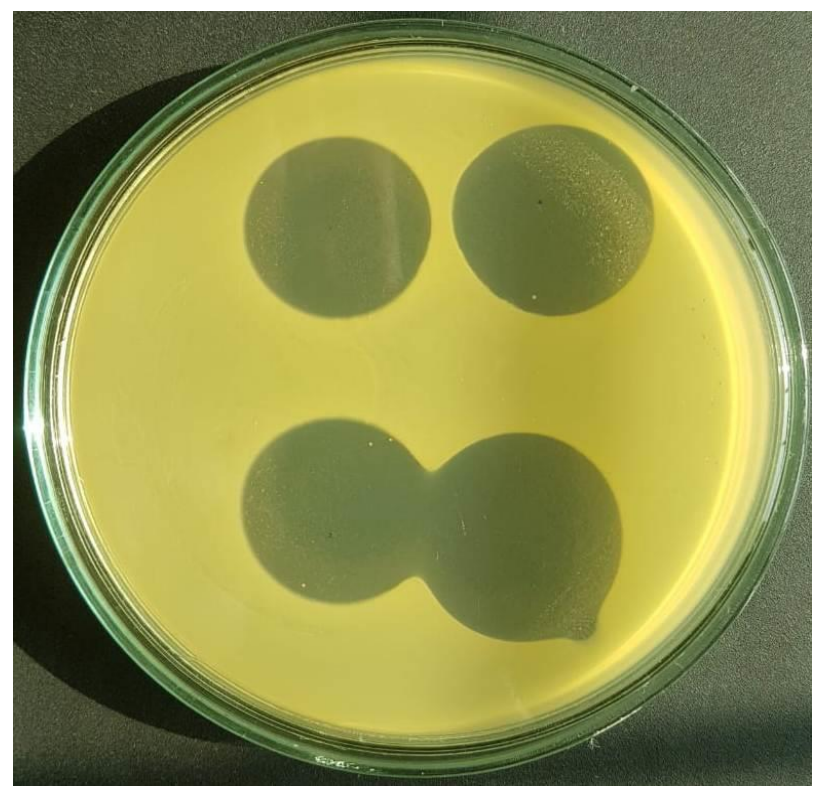

Fig. 2: Zones of Lysis showing positive spot test for suspected phages against $B$. abortus RB51

formation of phages as well as no loss in titres of phages was observed at $4^{\circ} \mathrm{C}$. While, one log reduction in titre was observed at freezing temperature $\left(-20^{\circ} \mathrm{C}\right)$ overnight. When a set of temperatures were analyzed statistically using univariate analysis of variance (ANOVA), non-significant difference $(P=0.14,0.67,0.06)$ was found in comparison of $25,37,45$ and $60^{\circ} \mathrm{C}$, respectively while significant $(P=0.00)$ difference was observed when compared higher temperatures of 70 and $80^{\circ} \mathrm{C}$. $\mathrm{pH}$ stability of phages showed that present study brucellaphages have stability between $\mathrm{pH}$ 7 to 9 , but acidic $\mathrm{pH}$ of 2 to 4 decreased the phage viability in one hour exposure (Fig. 6). Significant difference $(P=0.00)$ was present in comparison of acidic and basic $\mathrm{pH}$ values using ANOVA. There was no reduction in phage titres was observed in SM buffer and viability was 


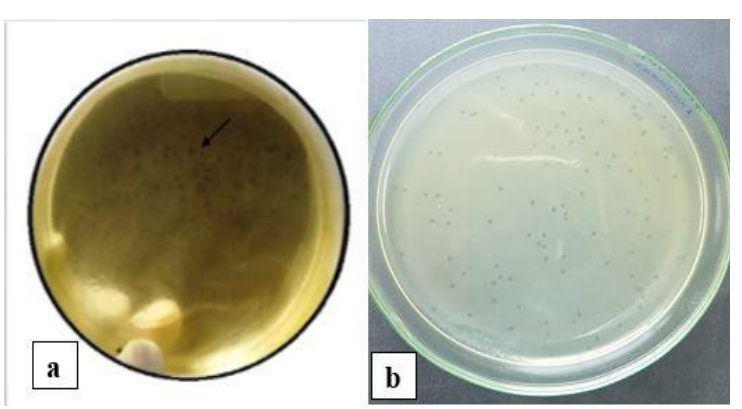

Fig. 3: Positive plaques of bacteriophages against $B$. abortus RB51. (a); pinpoint, hazy plaques of brucellaphages from first enrichment of slurry sample with $B$. abortus RB51 after incubation of $48 \mathrm{~h}$ at $37^{\circ} \mathrm{C}$, (b); pinpoint, clear plaques of $\phi \mathrm{P} 1$ after the addition of $\mathrm{CaCl}_{2}$ and $\mathrm{MgCl}_{2}$ in soft agar, successive enrichment of 3 to 4 times and use of $0.65 \%$ agarose for soft agar and incubation of $48 \mathrm{~h}$ at $37^{\circ} \mathrm{C}$

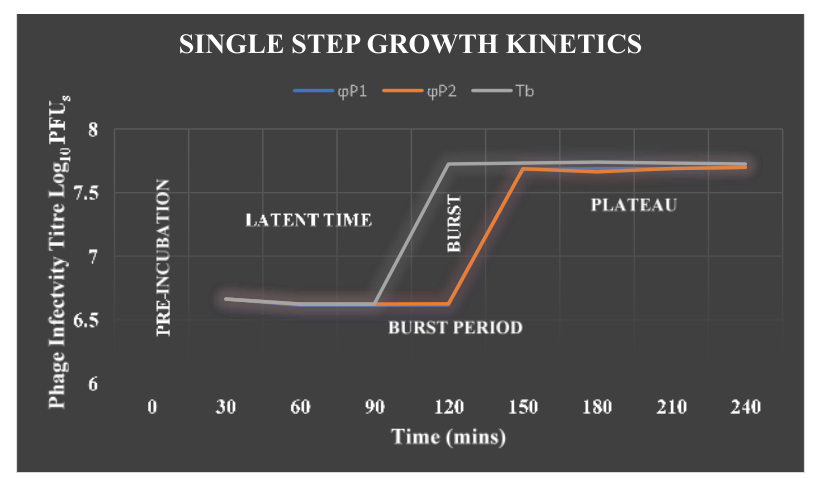

Fig. 4: One-step growth curves of brucellaphages. (a); $\phi \mathrm{P} 1$ (b); $\phi \mathrm{P} 2$ and $(\mathbf{c}) ; \mathrm{Tb}$

maintained overnight. No effect on viability of brucellaphages was observed after treatment with saline solution and EDTA. However, treatment with SDS and chloroform destroyed the brucellaphages in one hour exposure. Influence of inorganic salts on phages, showed a significant increase in PFU from $3.9 \times 10^{6}$ to $4.5 \times 10^{6}$ after the incorporation of $\mathrm{CaCl}_{2}$ and $\mathrm{MgCl}_{2}$ in the medium containing phage suspension. $\mathrm{NaCl}$ neither enhanced the plaque size nor lessened the PFU, showing neither a positive nor a negative effect on phage titre. Significant difference $(P=0.00)$ was observed in phage viability when treated with saline solution and EDTA in comparison with SDS and chloroform.

Nucleic acid extracts of theses phages were found resistant to RNase A and S1 nuclease but have sensitivity to DNase I enzyme. The genome sizes of phages were approximately $40 \mathrm{~kb}$ for two isolated brucellaphages and $\mathrm{Tb}$ phage (Fig. S1). HindIII digestion of the three phages depicted the two extra bands in $\mathrm{Tb}$ phage while the corresponding bands of $\sim 1000$ bp and $\sim 1800$ bp are absent in present study phages. EcoRI digestion of phages showed one extra band in $\mathrm{Tb}$ phage however other two phages have similar band patterns (Fig. S2). Characterization of proteins of isolated brucellaphages and $\mathrm{Tb}$ phage through SDSPAGE showed coomassie-stained bands of different sizes. The most prominent bands were of $45 \mathrm{kDa}$ and $70 \mathrm{kDa}$ in tested brucellaphages (Fig. S3).

Biocontrol activities of brucellaphages against live cultures of B. abortus RB51 and B. abortus S99 strains mixed in farm slurry in sham conditions showed the reduction in bacterial count at $24,36,48$ and $72 \mathrm{~h}$ time points (Table 2). This count was reduced to $10^{7}, 10^{5}$, and $10^{3}$ CFU/g after 24, 36 and $48 \mathrm{~h}$ treatment respectively. Negligible bacterial count reduction was observed before 12 $\mathrm{h}$ and count reduction became static after $72 \mathrm{~h}$ of treatment. Significant biocontrol activity $(P$-value $<0.05)$ was observed among three tested phages with specified titres in all treatments using ANOVA in three replicate experiments.

\section{Discussion}

The presence of bacteriophages against $B$. abortus was studied in several countries which established a close relationship between sensitivity of $B$. abortus cultures to lysis by phages. They used field isolates as well as vaccine strains of B. abortus in their studies (Zhu et al. 2009; Pandey et al. 2013; Farlow et al. 2014; Hammerl et al. 2014; Tevdoradze et al. 2015; Gupta and Saxena 2017a; Hammerl et al. 2017). Therefore, it is not astonishing to find lytic bacteriophages against $B$. abortus worldwide. In this study, we first established the optimized growth conditions for the host bacterial culture. For B. abortus, results of present study, declared that the use of conical Erlenmeyer flask instead of glass tube culture and shaking at $150 \mathrm{rpm}$ were critical for sufficient turbidity of $B$. abortus. The results showed that increased turbidity $\left(O . D_{600}=0.8\right)$ in flask could be due to shaking which provides aeration and splitting of bacterial clumps in the broth. Increased bacterial turbidity within $24 \mathrm{~h}$ could be advantageous to avoid phage resistance to host strain and for efficient phage propagation. Our observation of increased bacterial turbidity with increased aeration is correlated with Wundt (1957) observation, that growth of Brucella was greatly retarded by inefficient gas exchange when cultures were contained in 'tubes' though several liquid media were checked for the growth promoting capacity for Brucella. Gibby and Gibby (1964), also suggested that if active growth phase of Brucella is desired then its growth should be harvested before $24 \mathrm{~h}$ and counts of $B$. abortus growth declined slightly from 48 to $96 \mathrm{~h}$. Similarly, previous experiments of Gee and Gerhardt (1946), showed that the use of aerated liquid media, generation time of Brucella decreased as aeration was increased until aeration reached 2 volumes per min (volume of air to the volume of media).

In the present study, Tb phage produced pinpoint, round and clear plaques of $0.5 \mathrm{~mm}$ diameter but reached maximum of $2.0 \mathrm{~mm}$ after $48 \mathrm{~h}$ of incubation. Plaque morphology of present study brucellaphages $(\phi \mathrm{P} 1$ and $\phi \mathrm{P} 2)$ was same as of $\mathrm{Tb}$ phage i.e., pinpoint, round and clear 


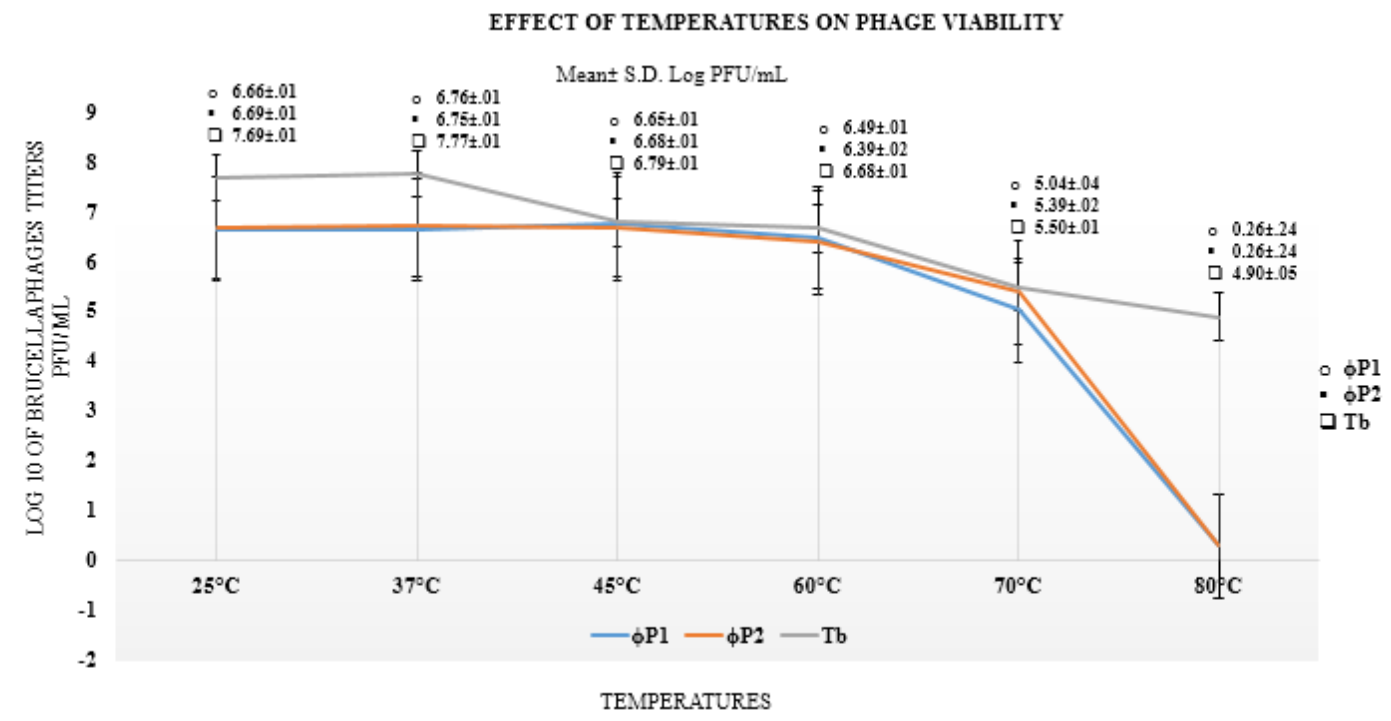

Fig. 5: Graphical representation of thermal stability of brucellaphages. Phage suspensions in TSB ( $\mathrm{pH}=7.0)$ were incubated for one hour at adjusted temperatures. Post treatment viability was assessed through double agar overlay technique. $\log _{10}$ values of phage titres (y-axis) were plotted against various temperatures (x-axis) for phage isolate $1(\phi \mathrm{P} 1)$, phage isolate $2(\phi \mathrm{P} 2)$ and positive control Tbilisi phage $(\mathrm{Tb})$. Data represent means \pm SD (standard deviation) of three independent experiments with similar results

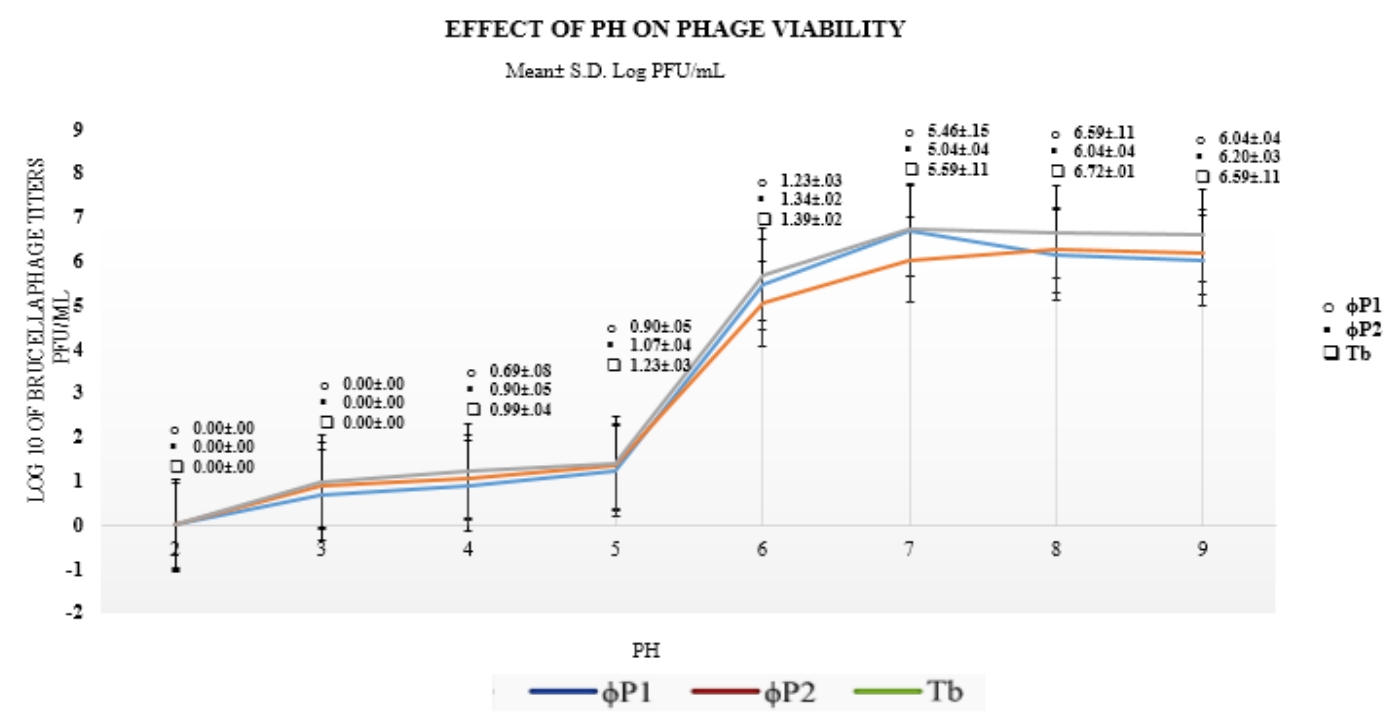

Fig. 6: Graphical representation of stability of brucellaphages at acidic and basic $\mathrm{pH}$ values. Phage suspensions in TSB adjusted in $\mathrm{pH}$ range 2 to 9 were incubated for one hour at $37^{\circ} \mathrm{C}$. Post treatment viability was assessed through double agar overlay technique. $\log _{10}$ values of phage titres (y-axis) were plotted against different $\mathrm{pH}$ values (x-axis) for phage isolate $1(\phi \mathrm{P} 1)$, phage isolate $2(\phi \mathrm{P} 2)$ and positive control Tbilisi phage $(\mathrm{Tb})$. Data represent means \pm SD (standard deviation) of three independent experiments with similar results with $95 \%$ confidence interval

plaques of $0.5 \mathrm{~mm}$ diameter. Both phages $(\phi \mathrm{P} 1$ and $\phi \mathrm{P} 2)$ have identical plaque morphology (round, clear and pinpoint plaques having $0.5 \mathrm{~mm}$ diameter) after $48 \mathrm{~h}$ of incubation at $37^{\circ} \mathrm{C}$. However, they were different in isolation source/sample nature i.e., one sample was found positive from slurry of livestock farm and other from sewage sample. Chachra et al. (2012); Pandey et al. (2013); Gupta and Saxena (2017b) and Saxena and Raj (2018) also found circular and clear plaques of $0.1-3.0 \mathrm{~mm}$ diameter of brucellaphages in their studies. In the present study brucellaphages were isolated from slurry samples of dairy farms on the $6^{\text {th }}$ day of incubation. It was attempted to isolate phages from the day 1 to day 5 but there was no indication of phage in sample. This finding is correlated with study of Chachra et al. (2012) and Pandey et al. (2013), in which they isolated brucellaphage from sewage sample of dairy farm on 
Table 2: Biocontrol activity of brucellaphages in sham experiment

\begin{tabular}{|c|c|c|c|c|c|c|c|}
\hline \multirow{2}{*}{$\begin{array}{l}\text { Bacterial target inoculum } \\
\text { (CFU/mL) }\end{array}$} & \multirow[t]{2}{*}{ Phage } & \multirow{2}{*}{$\begin{array}{l}\text { Phage titre tested } \\
\text { (PFU/mL) }\end{array}$} & \multicolumn{5}{|c|}{ Bacterial count reduction in $(\mathrm{CFU} / \mathrm{g})$ soil \pm standard deviation with time intervals } \\
\hline & & & $12 \mathrm{~h}$ & $24 \mathrm{~h}$ & $36 \mathrm{~h}$ & $48 \mathrm{~h}$ & $72 \mathrm{~h}$ \\
\hline \multirow[t]{3}{*}{ B. abortus RB51- $5.0 \times 10^{8}$} & $\phi \mathrm{P} 1$ & $5.0 \times 10^{11}$ & $4.6 \times 10^{8} \pm .009$ & $5.1 \times 10^{7} \pm .008$ & $6.8 \times 10^{5} \pm .006$ & $4.5 \times 10^{3} \pm .009$ & $4.3 \times 10^{3} \pm .010$ \\
\hline & & $5.0 \times 10^{8}$ & $4.7 \times 10^{8} \pm .009$ & $5.4 \times 10^{7} \pm .008$ & $7.3 \times 10^{5} \pm .005$ & $4.5 \times 10^{3} \pm .009$ & $4.5 \times 10^{3} \pm .009$ \\
\hline & & $5.0 \times 10^{5}$ & $4.7 \times 10^{8} \pm .009$ & $4.4 \times 10^{8} \pm .009$ & $3.8 \times 10^{7} \pm .011$ & $7.4 \times 10^{6} \pm .005$ & $7.1 \times 10^{6} \pm .006$ \\
\hline \multirow[t]{3}{*}{ B. abortus RB51- $5.0 \times 10^{8}$} & $\phi \mathrm{P} 2$ & $5.0 \times 10^{11}$ & $4.7 \times 10^{8} \pm .009$ & $6.1 \times 10^{7} \pm .039$ & $7.2 \times 10^{5} \pm .020$ & $4.8 \times 10^{3} \pm .009$ & $4.7 \times 10^{3} \pm .009$ \\
\hline & & $5.0 \times 10^{8}$ & $4.9 \times 10^{8} \pm .008$ & $5.5 \times 10^{7} \pm .007$ & $7.5 \times 10^{5} \pm .005$ & $5.0 \times 10^{3} \pm .008$ & $4.7 \times 10^{3} \pm .009$ \\
\hline & & $5.0 \times 10^{5}$ & $5.0 \times 10^{8} \pm .008$ & $4.5 \times 10^{8} \pm .009$ & $4.0 \times 10^{7} \pm .010$ & $7.9 \times 10^{6} \pm .005$ & $7.6 \times 10^{6} \pm .005$ \\
\hline \multirow[t]{3}{*}{ B. abortus S99- $5.0 \times 10^{8}$} & $\mathrm{~Tb}$ & $5.0 \times 10^{11}$ & $4.1 \times 10^{8} \pm .010$ & $4.9 \times 10^{7} \pm .008$ & $6.3 \times 10^{5} \pm .006$ & $4.0 \times 10^{3} \pm .010$ & $3.8 \times 10^{3} \pm .011$ \\
\hline & & $5.0 \times 10^{8}$ & $4.3 \times 10^{8} \pm .010$ & $4.8 \times 10^{7} \pm .009$ & $6.9 \times 10^{5} \pm .006$ & $4.2 \times 10^{3} \pm .010$ & $4.1 \times 10^{3} \pm .010$ \\
\hline & & $5.0 \times 10^{5}$ & $4.3 \times 10^{8} \pm .010$ & $4.1 \times 10^{8} \pm .010$ & $3.4 \times 10^{7} \pm .012$ & $7.1 \times 10^{6} \pm .006$ & $6.9 \times 10^{6} \pm .006$ \\
\hline
\end{tabular}

day sixth of incubation with actively growing stage of $B$. abortus. This could be because of the long generation time of the bacteria i.e., $4 \mathrm{~h}$ in liquid culture approximately as also reported by (McDuff et al. 1962).

Isolation and propagation of bacteriophages for $B$. abortus using spot assay method and double agar overlay technique for plaques in this study demonstrated that initial spot and plaque assays gave the evident positive results in enriched samples. It was revealed that bacteriophages were present and were able to infect $B$. abortus as lysis was apparent on the plates in our environment. Successive enrichment of three to four times, varying adsorption time, and addition of $\mathrm{CaCl}_{2}$ and $\mathrm{MgCl}_{2}$, we obtained the clear pinpoint plaques of brucellaphages. These results are in agreement with Chhibber et al. (2014) and Rasool et al. (2016) indicating the crucial importance of divalent ions, successive enrichment and adsorption time in adsorption of phage to the host cell surface. Adsorption time determined for present study phages corresponds to Tevdoradze et al. (2015) and Antadze et al. (2017) findings. Results for one-step growth kinetics of present study phages are in line with Jones et al. (1968) and McDuff et al. (1962).

Our observations for host range of present study brucellaphages indicated that they could not lyse heterogeneous bacterial species i.e., $S$. aureus, Streptococcus sp., Salmonella sp., E. coli, Bacillus subtilis, and $P$. multocida. Similar findings were demonstrated by Pandey et al. (2013) that their brucellaphage could not lyse any of the heterologous bacteria. Prajapati et al. (2014) also showed lytic activity of phage against $B$. abortus strain 99, S19 and 544 as well as B. melitensis Rev 1 and B. suis 1330, but did not show lysis against any of the heterogeneous bacterial species. Hence, these results determined that brucellaphage is specific for Brucella and not to other gram positive and gram-negative bacteria which is advantageous that other microflora in the body might not be disturbed.

In this study, stability of brucellaphages showed that their viability decreased when exposed to $70^{\circ} \mathrm{C}$ and beyond $70^{\circ} \mathrm{C}$ it completely became inactivated in one-hour exposure. They had stability at $\mathrm{pH} 7$ to 9 , but acidic $\mathrm{pH}$ of 2 to 4 decreased the phage viability in one-hour exposure. Stability of tested brucellaphages depicted that they retain their viability at $4^{\circ} \mathrm{C}$ but freezing temperature $\left(-20^{\circ} \mathrm{C}\right)$ were not revealed to be suitable for storage of phages as they lost their viability. Our results for temperature and $\mathrm{pH}$ stability of brucellaphages are correlated with Pandey et al. (2013) who found stability of brucellaphage at basic $\mathrm{pH}$, i.e. $\mathrm{pH} 8$ with survival rate of $75.31 \%$ after $48 \mathrm{~h}$ treatment. They also observed that at acidic $\mathrm{pH}$ of 2 to 4 , the phage titre was gradually decreased to zero and at $\mathrm{pH} 6$ phage titre was decreased only to $38.9 \%$ within 48 h. Gupta and Saxena (2017b) also studied inactivation of phage at $\mathrm{pH} 2$ and 4 after 4 and $12 \mathrm{~h}$ treatment. Our findings are also supported by Chachra et al. (2012) in favor of $\mathrm{pH}$ and temperature stability that high temperature of $70^{\circ} \mathrm{C}$ and acidic $\mathrm{pH}$ is lethal for brucellaphage viability. Evaluation of thermal stability and optimum $\mathrm{pH}$ conditions of brucellaphages are helpful to standardize the phage therapy as well as bio decontamination. Extreme resistance to temperature is advantageous for brucellaphages to apply in field conditions to keep phages working in harsh conditions.

Genome characteristics of our brucellaphages showed their nucleic acid to be double-stranded DNA of $40 \mathrm{~kb}$ size, resistant to RNase A and S1 nuclease but have sensitivity to DNase I enzyme. Restriction profile of $\phi \mathrm{P} 1$ and $\phi \mathrm{P} 2$ revealed that they have different migration patterns i.e., $\phi \mathrm{P} 2$ moved slower than $\phi \mathrm{P} 1$. This might be due to higher molecular weight of phage 2. These characteristics are supported by Zhu et al. (2009); Farlow et al. (2014); Hammerl et al. (2014); Tevdoradze et al. (2015) and Hammerl et al. (2017). Results of restriction of two phages revealed that they are different from positive control brucellaphage $\mathrm{Tb}$. The restriction endonuclease profiles were highly reproducible and consistent with phage $\mathrm{Tb}$. Restriction analysis of study phages ascertained that our brucellaphage isolates are closely related but they are different from $\mathrm{Tb}$ phage. Structural protein profile of present study phages by SDS-PAGE revealed two prominent bands of $45 \mathrm{kDa}$ and $70 \mathrm{kDa}$, which probably represents the major capsid proteins. Zhu et al. (2009) depicted nine bands, ranging from 40 to $85 \mathrm{kDa}$ of the structural proteins of Tbilisi phage. Similarly, Pandey et al. (2013), observed 4 bands of $65.98,60.46,48.56$ and $43.97 \mathrm{kDa}$ proteins in brucellaphage. Isolated phages need to be further characterized particularly protein segments of the isolated phages need to be investigated for their antibacterial ability against Brucella so that they may be used in the 
future for commercial lysate preparations. Biocontrol activity of our brucellaphages against live cultures of $B$. abortus RB51 and B. abortus S99 strains mixed in farm slurry in sham conditions showed significant reduction in bacterial counts when tested three of their titres. This count was reduced to $10^{7}, 10^{5}$ and $10^{3} \mathrm{CFU} / \mathrm{g}$ after 24,36 and $48 \mathrm{~h}$ treatment, respectively. Negligible bacterial count reduction was observed before $12 \mathrm{~h}$ and this might be due to longer generation time of Brucella $(4 \mathrm{~h})$ and $\log$ phase of $24 \mathrm{~h}$. Count reduction became static after $72 \mathrm{~h}$ of treatment. Plateau in reduction after $48 \mathrm{~h}$ might be due resistance or stability issues of phages which is an inherit limitation of our study. It needs to be investigated in future studies. Conferring literature reviewed, there is no such study conducted so far about the investigation of biocontrol activity of brucellaphages in vitro. Present study phages hold good antibacterial efficacy and can serve as biocontrol agents for the purpose of specific decontamination of Brucella. However, some issues remain to be controlled and studied as limitations of the present study such as the presence of toxic agents including endotoxin in the phage preparations, phage cocktails, stability and viability deficiencies, and the problem of bacterial resistance against phages.

\section{Conclusion}

In conclusion, this study provides base line for the investigation of indigenous bacteriophages for the field strains of B. abortus in laboratory in Pakistan. The isolated brucellaphages themselves have considerably more potential for further characterization. Therefore, more comprehensive studies are suggested in the future those might be molecular and genetic characterization including sequencing of phages, transmission electron microscopy, and in vitro and in vivo experimental evaluation of the isolated brucellaphages. Further studies could be designed to observe the bacterial resistance against the bacteriophages, needing a cocktail of bacteriophages to cover wide range of Brucella strains, presence of endotoxin in the phage preparations and stability and viability deficiencies. Subsequently, these bacteriophages can be used for the effective treatment of Brucella contaminated soil and environment of livestock and dairy farms, cost-effective diagnostics, and therapy of brucellosis using bacteriophages in different novel composition. Moreover, it will reduce the economic losses due to this deadly disease of dairy sector.

\section{Acknowledgment}

The authors gratefully acknowledge the financial support provided by Higher Education Commission (HEC) project \# 6782/Punjab/NRPU/R\&D/HEC/2016 under National Research Program for Universities, Pakistan and Denis Tremblay, (University Laval, Quebec City, QC, Canada) for the provision of positive control phage.

\section{Author Contributions}

AAS, ZA, MR and WS conceived and designed the study. AYS and AAS executed the experiments and analyzed the study results. MM helped in research work. All authors critically revised the manuscript for important intellectual contents and approved the final version.

\section{Conflicts of Interes}

The authors declare that they have no conflict of interest.

\section{Data Availability}

The data will be made avaialble on acceptable requests to the corresponding author.

\section{Ethics Approval}

Not applicable.

\section{References}

Ali S, S Akhter, H Neubauer, F Melzer, I Khan, EN Abatih, H El-Adawy, M Irfan, A Muhammad, MW Akbar, S Umar (2017). Seroprevalence and risk factors associated with bovine brucellosis in the Potohar Plateau, Pakistan. BMC Res Notes 10; Article 73

Antadze I, M Dadunashvili, T Burbutashvili, S Gunia, N Balarjishvili, E Tevdoradze, $\mathrm{T}$ Pataridze, RJ Obiso, $\mathrm{S}$ Hagius, $\mathrm{P}$ Elzer, $\mathrm{M}$ Kutateladze (2017). Diversity of phage-host specificity in Brucella Phage. J Bacteriol Mycol 4; Article id1049

Arif S, PC Thomson, M Hernandez-Jover, DM McGill, HM Warriach, K Hayat, J Heller (2019). Bovine brucellosis in Pakistan; an analysis of engagement with risk factors in smallholder farmer settings. Vet Med Sci 5:390-401

Chachra D, H Kaur, M Chandra, H Saxena (2012). Isolation, electron microscopy and physicochemical characterization of a brucellaphage against Brucella abortus vaccine strain S19. Intl J Microbiol 10; Article $2 \mathrm{c} 47$

Chhibber S, T Kaur, S Kaur (2014). Essential role of calcium in the infection process of broad-spectrum methicillin-resistant Staphylococcus aureus bacteriophage. J Basic Microbiol 54:775-480

Cutler SJ, AM Whatmore, NJ Commander (2005). Brucellosis-new aspects of an old disease. J Appl Microbiol 98:1270-1281

Dean AS, L Crump, H Greter, E Schelling, J Zinsstag (2012). Global burden of human brucellosis: A systematic review of disease frequency. PLoS Negl Trop Dis 6; Article e1865

Farlow J, AA Filippov, KV Sergueev, J Hang, A Kotorashvili, MP Nikolich (2014). Comparative whole genome analysis of six diagnostic brucellaphages. Gene 541:115-122

Filippov AA, KV Sergueev, MP Nikolich (2013). Bacteriophages against biothreat bacteria: Diagnostic, environmental and therapeutic applications. J Bioterr Biodef 3; Article S3-010

Gee LL, P Gerhardt (1946). Brucella suis in aerated broth culture: II aeration studies. J Bacteriol 52:271-281

Gibby IW, AM Gibby (1964). Population dynamics of Brucella on solid media. Appl Environ Microbiol 12:442-446

Gupta V, HM Saxena (2017a). A new bacteriophage based luminescence assay for diagnosis of brucellosis. Ind J Exp Biol 55:296-302

Gupta V, HM Saxena (2017b). Isolation and characterization of BpL1, a broad acting lytic bacteriophage against Brucella. Intl J Curr Microbiol Appl Sci 6:2486-2496

Hammerl JA, C Gollner, C Jackel, HC Scholz, K Nockler, J Reetz, SA Dahouk, S Hertwig (2017). Genetic diversity of Brucella reference and non-reference phages and its impact on Brucella-typing. Front Microbiol 8; Article 408 
Hammerl JA, SA Dahouk, K Nockler, C Gollner, B Appel, S Hertwig (2014). F1 and tbilisi are closely related brucellaphages exhibiting some distinct nucleotide variations which determine the host specificity. Genome Announc 2; e01250-13

Hamza A, S Perveen, Z Abbas, SU Rehman (2016). The lytic SA phage demonstrates bactericidal activity against mastitis causing Staphylococcus aureus. Open Life Sci 11; Article e00917

Jain L, M Rawat, A Prajapati, AK Tiwari, B Kumar, V Chaturvedi, H Saxena, S Ramakrishnan, J Kumar, P Kerketta (2015). Protective immune-response of aluminium hydroxide gel adjuvanted phage lysate of Brucella abortus S19 in mice against direct virulent challenge with B. abortus 544 Biologicals 43:369-376

Jones LM, G Merz, J Wilson (1968). Phage typing reactions on Brucella species. Appl Environ Microbiol 16:1179-1190

Manish K, C Puran, C Rajesh, R Teena, K Sunil (2013). Brucellosis: An updated review of the disease. Ind J Anim Sci 83:3-16

McDuff CR, LM Jones, J Wilson (1962). Characteristics of brucellaphage. $J$ Bacteriol 83:324-329

O'Leary S, M Sheahan, T Sweeney (2006). Brucella abortus detection by PCR assay in blood, milk and lymph tissue of serologically positive cows. Res Vet Sci 81:170-176

OIE (2019). Brucellosis (Brucella abortus, B. melitensis and B. suis) (infection with B. abortus, B. melitensis and B. suis). Manual of diagnostic tests and vaccines for terrestrial animalshttp://www.oie.int/fileadmin/Home/eng/Health_standards/tah m/3.01.04_BRUCELLOSIS.pdf

OIE (2018). Biosafety and Biosecurity: Standard for managing biological risk in the veterinary diagnostic laboratories and animal facilities. Manual of diagnostic tests and vaccines for terrestrial animals. https://www.oie.int/fileadmin/Home/eng/Health_standards/tahm/1.0 1.04_BIOSAFETY_BIOSECURITY.pdf

Pandey S, D Chachra, M Chandra, H Saxena (2013). Protein profiling and physico-chemical characterization of an isolated phage against Brucella abortus strain 19. Afr $J$ Microbiol Res $7: 1233-1238$

Prajapati A, D Ramchandran, H Verma, M Abbas, M Rawat (2014). Therapeutic efficacy of Brucella phage against Brucella abortus in mice model. Vet World 7:34-37
Rasool MH, R Yousaf, AB Siddique, M Saqalein, M Khurshid (2016). Isolation, characterization, and antibacterial activity of bacteriophages against methicillin-resistant Staphylococcus aureus in Pakistan. Jundishapur J Microbiol 9; Article e36135

Saxena HM, S Raj (2018). A novel immunotherapy of brucellosis in cows monitored non invasively through a specific biomarker. PLoS Negl Trop Dis 12; Article e0006393

Sergueev KV, AA Filippov, MP Nikolich (2017). Highly sensitive bacteriophage-based detection of Brucella abortus in mixed culture and spiked blood. Viruses 9; Article 144

Shafee M, M Rabbani, AA Sheikh, A Razzaq (2011). Prevalence of Bovine brucellosis in organized dairy farms, using milk ELISA, in Quetta City, Balochistan, Pakistan. Vet Med Intl 2011; Article 358950

Tevdoradze E, J Farlow, A Kotorashvili, N Skhirtladze, I Antadze, S Gunia, N Balarjishvili, L Kvachadze, M Kutateladze (2015). Whole genome sequence comparison of ten diagnostic Brucellaphages propagated on two Brucella abortus hosts. Virol J 12; Article 66

Texas (2011). Protocol: Phage enrichments. Center for Phage Technology Texas A\&M University, College Station, TX 77843. https://cpt.tamu.edu/wordpress/wp-content/uploads/2011/12/Phageenrichments-07-12-2011.pdf. (Accessed: April 4, 2016, last updated December 7, 2011)

Wang T, D Wang, Y Lyu, E Feng, L Zhu, C Liu, Y Wang, X Liu, H Wang (2018). Construction of a high-efficiency cloning system using the Golden Gate method and I-SceI endonuclease for targeted gene replacement in Bacillus anthracis. J Biotechnol 271:8-16

Wong CL, CC Sieo, WS Tan, N Abdullah, M Hair-Bejo, J Abu, YW Ho (2014). Evaluation of a lytic bacteriophage, $\Phi$ st1, for biocontrol of Salmonella enterica serovar Typhimurium in chickens. Intl J Food Microbiol 172:92-101

Wundt W (1957). Untersuchungen zur Entwicklung leistungsfahiger brucellennahrboden. Zentralbl Bakteriol Orig 165:393-402

Yang H, L Liang, S Lin, S Jia (2010). Isolation and characterization of a virulent bacteriophage $\mathrm{AB} 1$ of Acinetobacter baumannii. BMC Microbiol 10; Article 131

Zhu CZ, HY Xiong, J Han, BY Cui, DR Piao, YF Li, H Jiang, Q Ren, XY Ma, YM Chai, X Huang, HY Zhao, LY Li (2009). Molecular characterization of $\mathrm{Tb}$, a new approach for an ancient brucellaphage. Intl J Mol Sci 10:2999-3011 